Running head: AMBIDEXTROUS LEADERSHIP

\title{
Ambidextrous Leadership for Innovation: The Influence of Culture
}

\author{
Ronald Bledow \\ Ghent University, Belgium \\ Michael Frese \\ National University of Singapore, NUS Business School, Singapore \\ and Leuphana, University of Lueneburg, Germany
}

Verena Mueller

Jacobs University of Bremen, Germany

Acknowledgement: Work on this chapter was supported by a research grant of the Volkswagen Foundation (II/82 408). 


\begin{abstract}
We develop a new look on leadership for innovation and propose that effective leaders alternate between a broad range of behaviors and tune their approach to the changing demands of innovation. This is referred to as ambidextrous leadership. As the importance of different leader behaviors varies not only across time but also across contexts, ambidextrous leadership takes different shapes depending on contextual conditions. We discuss culture as an important contextual condition that holds implications for effective ambidextrous leadership. Cultures have different strengths and weaknesses for innovation that can be leveraged or compensated. We use the cultural characteristics identified by the GLOBE project to discuss how leaders can take culture into account when leading for innovation.
\end{abstract}




\section{Introduction}

The complexity leaders in today's organizations need to manage is unprecedented. Two factors that contribute to this complexity are the high pressure for innovation on today's markets and continuing internationalization. Innovation amplifies complexity because it involves a variety of partly conflicting activities leaders need to engage in (Bledow, Frese, Anderson, Erez, \& Farr, 2009a). Leaders need to stimulate creativity among their followers and at the same time streamline their business. Internationalization of firms is a second factor that increases complexity and poses challenges for leadership. For many leaders it has become common to work in different cultural contexts during their career and to lead employees with diverse cultural backgrounds.

In this chapter, we focus on the interface of innovation and internationalization and the associated challenges for leadership. We address the question how leaders can respond to the complexity of innovation and adapt their leadership approach to be effective innovators in different cultures. To do so, we integrate research findings based on a new look on leadership for innovation and derive practical implications. The new look suggests that it is not the commitment to any one specific leadership style that is most effective for innovation. Instead, it suggests that leaders need to flexibly alternate between different behaviors and adapt their approach to different situations based on an understanding of the conflicting forces underlying innovation.

\section{The new look on leadership for innovation}

The new look on leadership for innovation is characterized by three core features: A functional approach, the concept of duality, and a focus on dynamics. By taking a functional approach, we start our analysis with the demands of innovation, in terms of the requisite activities individual employees and collectives of employees perform to innovate. The 
effectiveness of leadership depends on how functional or dysfunctional the behavior of a leader is in stimulating and balancing the activities underlying innovation. An important principle of a functional approach is that the job of the leader it to get done, whatever is not being effectively handled by employees themselves (McGrath, 1962). For instance, a team may produce a variety of high quality ideas for a marketing campaign but fall short when it comes to persistently pursuing any one idea until it is fully implemented. From a functional approach an effective leader needs to complement this shortcoming of a team by ensuring focused persistence.

The second core feature of the new look on leadership for innovation is the concept of duality. We suggest that understanding and embracing the dualities involved in innovating enables leaders to make informed decision in adapting their leadership approach. The term duality refers to pairs of concepts that are parts of a larger whole (Farjoun, 2010). Examples of dualities relevant for innovation are: the differentiation between exploration and exploitation as fundamental different forms of organizational learning (March, 1991); the separation of innovation into the two phases of idea generation and idea implementation (e.g., Nakata \& Sivakumar, 1996); the classical distinction between task-oriented and peopleoriented behavior in leadership (Stogdill \& Coons, 1957). In all these cases, a broad phenomenon is separated into distinct parts for the purpose of a precise analysis. The parts are often mutually exclusive categories or even antithetical, for instance March (1991) emphasized the antithetical relationship between exploration and exploitation. By conceptualizing pairs of concepts as dualities, we emphasize not only the differences and contradictions that arise between the parts of a duality, but also their fundamental interdependence and the necessity for leaders to embrace both parts of the dualities of innovation (Farjoun, 2010). Both sides of the dualities we will discuss have some functional value for innovation and it is the ability of leaders to find the right balance for a particular context and to overcome contradictions that contribute to successful innovation. 
The third core feature of the new look on leadership for innovation is its focus on dynamics which is directly related to the concept of dualities. Innovation requires mind sets and activities that are not compatible at any point in time. For instance, innovators need to engage in unconventional thinking and translate new ideas into the daily routine of an organization. Conflicting activities need to be performed and integrated sequentially (see Figure 1). Effective leadership can therefore not rely on one fixed set of leader behavior that is consistently performed across time. Supporting unconventional thinking may be effecting at one point in time but may become maladaptive at a later point in time when employees face routine tasks that need to be performed in an efficient manner. Over time leaders therefore need to flexibly adapt their leadership approach and alternate between different behaviors in accordance with the task demands of innovation.

\section{Dualities of innovation}

A distinctive characteristic of innovating is the variety of activities that need to be performed in order to successfully create something new (Bledow et al., 2009a). Creative ideas that depart from or even challenge the status quo need to be developed, they need to be scrutinized for their usefulness and feasibility and they require promotion within a team or organization to succeed on the marked of ideas (Farr, Sin, \& Tesluk, 2003). If a new idea finds sufficient support, its implementation needs to be planned and the required resources need to be obtained. In the process of implementation adaptations to the original ideas may need to be made and the idea needs to be integrated into the routines of an organization. To do so, high degrees of coordination among members of a team, attention to details of problems and persistence are required. This non-exhaustive list of activities underlying innovation illustrates that innovation cannot be reduced to anyone specific activity such as engaging in creative idea generation. Innovation requires the integration of a variety of different activities. 
Researchers have used different pairs of concepts to organize and differentiate the activities needed for innovation. We view these distinctions as dualities. The distinction between exploration and exploration contrasts explorative activities such as risk taking, experimentation, and discovery with exploitative activities such as refinement, production, and efficient execution (March, 1991). Sheremata (2000) makes the differentiation between knowledge generation and knowledge integration as the two fundamental categories of activities that are needed for innovation. Concerning the innovation process, phase models highlight the different activities that are performed during phases of idea generation and phases of idea implementation (Nakata \& Sivakumar, 1996).

A common theme related to the conceptual distinctions above is the notion of tensions, paradoxes, and contradictions between the two sides of each distinction (e.g., Benner \& Tushman, 2003; Lewis, Welsh, Dehler, \& Green, 2002). Innovation would be a less difficult endeavor if the activities described by each pair of concepts would be easily reconcilable. However, these activities compete for scarce resources, can inhibit each other, and are facilitated by different factors such as mindsets, leadership behaviors or cultural values. A playful and creative state of mind rarely goes hand in hands with a mindset focused on analyzing problems during implementation. Rarely are people good at paying attention to detail, conforming with organizational rules, and also engaging in innovative behavior (Miron, Erez, \& Naveh, 2004). Diversity in a team can be a resource for creativity but can come at the cost of efficient coordination (Kearney \& Gebert, 2009).

The new look on leadership for innovation views the pairs of conflicting activities as dualities and suggests that understanding them as dualities provides the basis for an improved management of innovation. Whereas tensions and trade-offs exist between the parts of a duality such as exploration and exploitation, they are also mutually dependent (Farjoun, 2010). Exploitation ensures that there are sufficient resources available for explorations and 
exploration ensures that new processes and products are created that can be exploited at a later point in time. Concerning the duality of knowledge generation and knowledge integration, one depends on the other. Generation of diverse knowledge is the prerequisite for knowledge integration and integrated knowledge provides the basis from with people can explore and develop new knowledge. Creativity and idea implementation - the duality of the innovation process - are also not only conflicting but also intertwined activities. Creative new ideas depart from what was previously implemented but are at the same time strongly influenced by what previously existed. For instance, although cars were invented to overcome the limitations of traditional means of transportation, the first cars were strongly influenced by the design of horse carriages. Only through repeated intertwined cycles of idea creation and idea implementation did the modern car emerge.

The presence of tensions as well as interdependencies between the parts of the dualities of innovation hold important implications for leaders. Tensions need to be actively managed and interdependencies need to be accounted for. Leaders need to switch back and forth between promoting employees activities that belong to each side of a duality such as knowledge generation and knowledge integration (Bledow et al, 2009b; Rosing, Frese, Rosenbusch, 2009). A rigid approach to leadership that relies on a narrow range of behaviors does not suffice for innovation. Our next step is therefore to develop a model of ambidextrous leadership for innovation that emphasizes flexibility and context sensitivity of leadership.

\section{Ambidextrous leadership for innovation}

Past research confirms the necessity of a new look on leadership for innovation (Anderson, De Dreu, \& Nijstad, 2004). Empirical research has demonstrated that leadership is one of the most important means to stimulate and ensure the success of innovation, however, it is unclear about the specific leaders behaviors that contribute to innovation success. Metaanalytic evidence suggests that very different leadership styles show positive relationships 
with innovation, among others participative leadership, initiating structure, and transformational leadership (Hulsheger, Anderson, \& Salgado, 2009b). Moreover the magnitude between each leadership style and innovation outcomes varies highly across studies. These findings suggests two points: First, very different leader behaviors can contribute to innovation and second, the relative importance of different leader behaviors varies depending on context.

We use the term ambidextrous leadership to provide an outline of leadership for innovation that is based on an understanding of the dualities of innovation and that acts on this understanding. Ambidextrous leadership can imply antithetical behaviors depending on the particularities of a situation. It can imply that a leader demands of a team to focus all its efforts in a tightly coordinated fashion on achieving a goal the leader points out in detail. It can also imply that a leader encourages a team to search broadly for new ideas unconstrained by the status quo and the possibilities the leader is considering. Ambidextrous leadership can entail that a leader structures roles and procedures and controls if team member adhere to his or her specifications. It can also imply that leaders inspire a team but restrain from interfering with active self-regulation of a team.

Ambidextrous leaders ensure an overall equilibrium of forces that support either part of the dualities underlying innovation. The set of leader behaviors suitable for attaining an overall equilibrium constantly changes as a collective of employees moves ahead on a project. Ambidextrous leaders realize if members of a team move to the extremes of developing ever more new and divergent idea. They take action to establish a common focus that integrates the best ideas and discards other ideas such that a team can move forward. At a later point in time, the team may get locked into its routines and may be unable to envisage new ways of doing things. In such a situation, an ambidextrous leader may demand a team to question itself or expose team members to divergent viewpoints. 
Ambidextrous leadership demands cognitive and behavioral complexity as a broad range of seemingly conflicting behaviors need to be performed over time (Buijs, 2007; Denison, Hooijberg, \& Quinn, 1995). It also requires the flexibility to constantly adapt one's leadership approach to the changing demands of innovation. The demands of innovation do not change in a linear and foreseeable manner. Innovation is characterized by an iterative cycle of well-planned and more chaotic episodes and leaders need to constantly respond to and influence these cycles, for instance, by moving back and forth between stimulating knowledge generation and ensuring knowledge integration (Lewis et al., 2002).

Besides the ability to dynamically adapt one's leadership approach to changing task demands, ambidextrous leadership requires sensitivity to the context a leader is embedded in. An effort to develop a radically new product requires a different equilibrium of forces than adaption of an existing line of products to a new customer. In the first case, a leader needs to place more emphasize on intellectual stimulation and exploration, whereas in the later case structuring and streamlining by the leader are relatively more important (Keller, 2006).

An important contextual feature to which a leader needs to adapt his or her approach is enduring characteristics of the team. For example, some teams lean towards exploration because they are composed of many highly creative team members. In such a team a leader will only rarely need to stimulate further creativity and instead place more emphasis on counterbalancing the one-sided focus of the team. In such a team, a leader may push team members to work more closely together such that the ideas they develop build on each other or the leader may ask team members to critically focus on the feasibility of new ideas. Other teams may be highly ambidextrous themselves, that is they self-regulate the demands of innovation by autonomously switching between the requisite activities. In such a case, a leader will only rarely need to intervene to ensure an equilibrium of forces and can focus his 
or her efforts on establishing a supportive environment in which the team can leverage its ability.

The important point made by the concept of ambidexterity is that in any case, it is necessary to keep an eye on both sides of the dualities of innovation. It is the relative importance of each side of a duality for a given context that differs but it is never sufficient for leaders to focus on one at the expense of the other over longer periods of time. For instance, even in highly exploitative environments such as productions departments a certain amount of exploration is crucial. New ideas can increase efficiency of production and the availability of alternative way to perform a task can become essential when unforeseen turbulence occur (Emery \& Trist, 1969; Farjoun, 2010).

In the following, we discuss how the theoretical approach we have outlined can inform leaders to make effective decision concerning four areas of leadership: Composing teams, structuring tasks, managing decision making, and influencing follower motivation.

\section{Composing teams}

The new look on leadership for innovation can assist leaders in making effective decisions when composing teams such as new product development teams or cross-functional project teams. Our analysis suggests that leaders should not focus on only selecting creative team members. Instead the duality perspective suggests that high levels of creativity are necessary but not sufficient for composing teams that are successful at innovating. Successful teams also need members who are sensitive to the rules and regulation of the organization in which the team is embedded and team members who are good at working out the details of innovation. In line with this reasoning, Miron-Spector, Erez, and Naveh (2006) found that the most innovative teams were composed of a majority of highly creative people and additional members who brought complementary characteristics such as attention to detail and 
conformism to a team. Beyond composing such teams, leaders can improve team processes by stimulating reflection on combining and counterbalancing strengths and weaknesses of different team members (Arbel and Erez, 2008).

Diversity in terms of the functional background of team members but also diversity concerning gender, age or race is often viewed as a driver of innovation because of the variability of knowledge that accompanies diversity (Shin \& Zhou, 2007). Concerning functional diversity, research has indeed found that diverse teams are more innovative (Hulsheger, Anderson, \& Salgado, 2009a). The duality perspective suggests, however, that diversity is not enough. Diversity provides the raw material in terms of divergent knowledge that can be combined but diversity alone can also result in inferior communication and coordination (Van Knippenberg, De Dreu, \& Homan, 2004). Diversity needs to be complemented with integration mechanisms to come to fruition. The vision and a shared identity a leader communicates is an example of a mechanism that can offset potential risks of diversity and leverage its strengths (Kearney \& Gebert, 2009; Shin \& Zhou, 2007). Fostering understanding of the value of diversity among team members is a further means by which leaders can ensure that composing diverse teams pays off (Homan, van Knippenberg, Van Kleef, \& De Dreu, 2007).

\section{Structuring tasks}

Leaders can also influence success of innovation by effectively structuring tasks and activities. One strategy is to separate the different activities underlying innovation to different people or departments (Bledow et al., 2009a). For instance, explorative business units can be created in an organization to pursue innovation unconstrained from established business areas (Tushman \& O'Reilly, 2006). Within a team, fixed and specialized roles can be created to separate creative tasks from innovation implementation and routine day to day processes.

Over time, the innovation process can be segmented into distinct phases of idea generation in 
which broad and unconventional thinking is promoted and phases of implementation in which adherence to rules is demanded.

The rational of a strategy of separation is that separation reduces tensions between different activities and increases efficiency of each activity. If roles are separated, individuals can be selected to and focus on roles according to their strengths, for instance on their creative ability or on their precision and speed in performing repetitive tasks (Miron-Spector et al., 2006). If distinct departments are created, different leadership approaches, reward systems, and work practices can be installed that match the tasks of each department. However, leaders need to be aware that complete separation of the activities of innovation is not feasible and not desirable. Both parts of the dualities of innovation are interdependent and separation of activities can come at the cost of such interdependencies (Bledow et al., 2009a). For instance, companies who have moved their production to low-costs countries have anecdotally reported that the production-base was no longer available as a source of new ideas. Leaders who promote exploration and creativity only in roles and departments that are explicitly established for this purpose may risk valuable creative potential because the available expertise on all levels and in all business units of a company can serve as the source of useful new ideas.

The logic of dualities suggests that the strategies of separating innovation activities in an organization or team, is accompanied by the need to install mechanisms that ensure reintegration. Research has found integration of activities in the top management team to be particularly important if organizational units are separated along the lines of explorative and exploitative activities (Jansen, George, Van den Bosch, \& Volberda, 2008). Integration by the leader may also be particularly important in teams that are structured around fixed roles. However, integration at higher hierarchical levels is not sufficient. Linkages are needed among employees and managers at all levels, for instance by means of boundary spanners and 
informal networks. Such linkages ensure constant knowledge flows across separates roles in a team or across organizational units.

We caution against a one-sided focus on structural separation and have argued in favor of an integrated approach in which the conflicting activities of innovation are actively managed rather than reduced (Bledow et al., 2009a). Throughout an organization the activities referred to by the parts of a duality such as exploration and exploitation need to be stimulated, balanced and integrated. The combination of complementary strategies which we have discussed under the label of ambidextrous leadership serves this goal.

\section{Managing decision making}

Concerning decision making, tensions exist around the degree of directives and control a leader imposes and the degree of autonomy that is delegated to employees. Whereas a directive approach can ensure alignment and integration of employees' activities, autonomy allows employees to generate and explore new ideas. We argue here that high autonomy, high directiveness and a combination of both approaches can work or fail, depending on whether or not mechanisms are in place that counterbalance the downsides of each approach.

Success or failure of a primarily directive approach to leadership depends on the ability of a leader. If knowledge and abilities of a leader for a specific task are higher than those of subordinates, a directive approach to leadership is advisable (Murphy, Blyth, \& Fiedler, 1992). By being directive, leaders ensure that their creativity and expertise is made use of and results in high quality decision throughout the process. However, rarely do leaders have more information available on all aspects of an innovation than their followers. In crossfunctional teams expertise is distributed among team member and in production teams detailed knowledge about production processes often resides among workers (Emery \& Trist, 
1969; Hoegl \& Parboteeah, 2006). In these cases, autonomy that allows employees to explore is required.

Although a leadership approach that grants high autonomy to employees fosters exploration of new ideas (Shalley, Zhou, \& Oldham, 2004), it also holds risks for innovation success. Employees may pursue ideas that are not compatible with an organization's goals and the activities of different employees may not be aligned (Gebert, Boerner, \& Lanwehr, 2003). Our theoretical perspective suggests that high autonomy is only successful if mechanisms are present that counterbalance the downsides of high autonomy. A leader may ensure that team members align their activities by designing interdependent tasks and by providing an overall goal which employees can only achieve through cooperation. Bledow and Farr (2009) showed that the strategy of leaders to provide high autonomy during innovation implementation was only effective if there was also a high level of initiative in the team. They argue that high autonomy holds the risk that team members do not actively selfregulate the task of innovation implementation. High degrees of initiative counterbalance this risk.

The concept of ambidextrous leadership further suggests that the strategies of providing autonomy and being directive can be combined in an overall leadership approach. A leader may flexibly switch between both strategies from task to task and from employee to employee. For instance, a leader may be directive concerning the overall goal of a new product development effort and on aspects of the task on which the leader has the best information available. The leader may hand over decision-making to team members wherever their expertise is superior and provide each team member with time to autonomously explore. Creating such a synergy between autonomy and directiveness holds the potential to be most effective if leaders and team members manage to coordinate their decisions.

\section{Influencing motivation}


One important pathway through which leaders influence success or failure of innovation is their impact on motivation of employees. Motivation refers to both the degree and the direction of employee's efforts. Transformational leadership is a leadership style that increases follower motivation and that can focus employee's effort on the success of innovation (Keller, 2006). Transformational leaders provide intellectual stimulation and individual consideration to stimulate followers' creativity and explorative activity. Transformational leaders also give direction by formulating an inspiring vision to go beyond ordinary levels of performance. Although transformational leadership is in general related to innovation success (Hulsheger, Anderson, \& Salgado, 2009b), a one-sided focus on showing transformational leader behavior is ill-advised.

At the very heart of the concept of transformational leadership is the idea of change. Change and stability form a duality and our theoretical rational suggests that even though innovation is about creating change, leadership behavior that supports stability can also contribute to innovation success (Farjoun, 2010). Standardized business processes in a department and efficient routines of individuals can provide the basis for innovation (Gilson, Mathieu, Shalley, \& Ruddy, 2005). Standardization and routinization increase efficiency and free up resources that can be devoted to creativity and explorative activity (Ohly, Sonnentag, \& Pluntke, 2006). Reliable and predictable procedures can facilitate integration and alignment of the activities of different employees. And at the end point of the innovation process, newly created products and processes need to be transformed into stable business routines in order to be exploited and leader behavior is required to manage this transition.

Past research has identified sets of leader behavior that can have a positive impact on the innovation process because they foster the requisite stability of processes and alignment among employees (Dayan, Di Benedetto, \& Colak, 2009; Keller, 2006). Transactional leadership and initiating structure are concepts that refer to leader behavior which can serve 
this function: structuring fixed roles and responsibilities, specifying detailed goals and guidelines, controlling adherence to rules, providing contingent rewards for desired behaviors, taking corrective action and sanctioning errors. However, by itself such a leadership approach can inhibits creativity and constrains the momentum of innovation. It will only contribute to successful innovation if it is accompanied by mechanisms that stimulate exploration and change such as a transformational vision or goals that explicitly demand creativity (Shalley, 1991).

Leader needs to adapt their approach to influence the direction of efforts of individual employees and teams based on an understanding of the duality of innovation. If there is momentum for change and passion for innovation among employees, leaders need to not only stimulate and channel these motivational forces but also engage in complementary behaviors that create stability. In contrast, if employees perform tasks in a streamlined but rigid manner, leaders need to counterbalance the one-sided focus of a team by questioning the status quo and creating momentum for change. Ambidextrous leaders are able to fuel passion and to ensure discipline (Andriopoulos \& Lewis, 2009). As a team proceeds on a project, ambidextrous leaders are responsive to different motivational challenges and adapt their leadership approach accordingly. The fine line leaders need to walk on is to synergize complementary motivational forces such as passion and discipline rather than strengthening one at the cost of the other. In a next step, we will discuss how effective ambidexterous leadership varies depending on the cultural context.

\section{Culture and leadership for innovation}

The rate and success of innovation varies between nations and culture contributes to these differences (Shane, 1992, 1993). We understand culture as the common values and practices of people - these common values and practices produce a certain cohesiveness among national cultures or subcultures (House \& Javidan, 2004). Although there are 
differences between national cultures in the level and success rate of innovation (Shane, 1993), people in all cultures can and have to innovate. Historically, breakthrough innovations have emerged from cultures very different from the cultures that produce most of today's innovations (e.g. ancient China and ancient Egypt). This suggests that different cultures can promote innovation and that there is no "one-best-culture" for innovation. However, innovators may face different challenges depending on cultural characteristics and the leadership tasks may vary across cultures. A crucial question therefore is how leaders can promote innovation success within a given cultural context.

In the following, we address the question how leaders can take cultural characteristics into account when managing innovation based on the new look we have proposed. The new look on leadership for innovation suggests that cultural characteristics may have both functional and dysfunctional consequences for innovation because innovation requires a variety of partly conflicting activities. More specifically, characteristics of a culture facilitate some of the processes underlying innovation such as development and exploration of new ideas and simultaneously inhibit other processes necessary for innovation such as well coordinated and efficient implementation (Nakata \& Sivakumar, 1996). A culture with a high acceptance of hierarchical structures and authority of leaders is, for instance, detrimental for autonomous exploration and creativity of employees. However, if a leader in such a culture commits to a certain innovation and provides clear instructions on how to implement it, the cultural context may facilitate fast and streamlined implementation (Westwood \& Low, 2003).

For leadership this implies that the set of leader behaviors that contribute to innovation success varies across cultures. Although general principles of leadership may apply across cultures because of general psychological laws, the specific behavior leaders need to engage in may vary. Copying practices that have been successful in one cultural context is therefore 
unlikely to always translate into innovation success in a different cultural context. If leaders work in different cultures and interact with members with diverse cultural backgrounds, they need a good understanding of the culture and need to be able to tune their leadership approach to cultural characteristics.

The new look on leadership for innovation can help to inform leaders how to respond to cultural difference. On a general level, it suggests a dual strategy: Leaders need to recognize the functional strengths of a certain culture for innovation, create situations that allow these strengths to unfold, and restrain from actions that interfere with these strengths. On the other hand, leaders need to be aware of the weaknesses of a certain culture for innovation and take action to counterbalance these weaknesses. For instance, in a cultural context in which employees are not used to question established ways of doing things a focused initiative by a leader may be necessary to stimulate reflection and creativity.

In the following, we apply this general rational to specific culture characteristics. We follow the model of cultural characteristics developed by the GLOBE study (House, Hanges, Javidan, Dorfman, \& Gupta, 2004). The GLOBE study has refined the prior model of Hofstede (1991) and differentiates between values ("should be") and practices ("as is") dimensions of culture (Hanges \& Dickson, 2004). This distinction is important because it has been shown that the societal practices are more strongly related to objective societal facts and that societies often contrast their current practices with an ideal that deviates from these practices (Gupta, de Luque, \& House, 2004; Hanges, 2004; Javidan, House, \& Dorfman, 2004). For effective leadership of innovation the actual practices in a culture are important and we therefore limit our discussion to cultural practices.

For each cultural characteristic, we discuss beneficial and detrimental consequences for innovation and propose how leaders may adapt their approach to respond to cultural characteristics. Table 1 provides the short definitions of each cultural "as is"- dimension from 
the GLOBE project (Javidan et al., 2004, p. 30) and lists the results on the as-is dimensions for five countries - China and the US, Brazil as the new giant in South America, Germany as the most important economic country in Western Europe, and Zimbabwe as an example for Black Africa (data were ascertained before the current political and economic crisis of Zimbabwe). A summary of our propositions is provided in Table 2.

Insert Tables 1 and 2 about here

\section{Future orientation and uncertainty avoidance}

We discuss the cultural dimensions future orientation and uncertainty avoidance together because they are highly correlated (Hanges, 2004). Both cultural dimensions imply that people are concerned about the future, because of anxieties (uncertainty avoidance) or because they know that the future is important (future orientation). China is an interesting exception to this high correlation as China is high on worries about the future but there is little future oriented behavior otherwise.

Germany is a country well known for its high degrees of uncertainty avoidance (some people have talked about the "German Angst") (Hofstede, 1980). A problematic consequence of uncertainty avoidance for innovation is that employees may not dare to try out something new because there is always uncertainty whether or not novel ideas will work. Although uncertainty avoidance is frequently assumed to be detrimental for innovation (e.g., Jones \& Davis, 2000), empirical evidence is inconsistent and our theoretical approach suggests a more differentiated picture. We assume that uncertainty avoidance may in some conditions actually stimulate innovation and promote certain kinds of innovation. 
If external conditions such as the market environment change and create uncertainty, uncertainty avoidance may motivate people to innovate because innovation can be a means to gain higher levels of certainty. If employees realize that the context they work in has changed and that the traditional way of accomplishing a task no longer works, innovation is a sheer necessity. People in uncertainty avoidant cultures should be particularly responsive to such a problematic situation and innovate to reduce uncertainty. This may not produce unconstrained creativity but rather a focused problem solving approach to innovation. Leaders in uncertainty avoidant cultures may stimulate innovation by pointing out its necessity to be successful in an uncertain future.

Depending on the degree of uncertainty avoidance, leaders will need to counterbalance a one-sided focus in the innovation process. Innovation usually proceeds with episodes of well-planned linear development and chaotic and emergent episodes in which it is difficult to stay focused (Lewis, 2000). In high uncertainty avoidance cultures there is a tendency towards proceeding in a well-planned manner. A leader may, therefore, need to compensate for this cultural imprinting by stimulating reflection, experimentation, and questioning of one's prior approaches so that employees do not just follow a rigid approach or prematurely commit to an idea. In contrast, in a low uncertainty avoidant culture, a leader may need to push the team towards closure by specifying clear goals, deadlines, and plans of action.

Uncertainty avoidance also influences the kind of innovations members of a culture tend to generate and leaders can compensate this tendency to ensure a balance between different kinds of innovation. For example, Lin (2009) showed that more process management and technological innovations were introduced in the automotive industry in countries high in uncertainty avoidance. High uncertainty avoidance promotes incremental innovation such as continuous improvements in car manufacturing or adaptations of existing products to new customers. High uncertainty avoidance and a one-sided focus on incremental innovations can 
come at the cost of considering more radical innovations that are required to remain

competitive on highly dynamic markets. In such a cultural environment, leaders may need to enlarge employee's focus and stimulate unconstrained creativity so that employees try out entirely new opportunities. In contrast, in an uncertainty accepting cultural environment leaders may need to prevent an overemphasis of exploratory behavior and ensure exploitation and adaptation of current processes and products.

Future orientation similarly makes it possible for leaders to align people behind future goals easily; thus it may be easy to show that future opportunities and problems will appear and should be planned for right now. Also, one should sacrifice now for future goals.

Planning is the most important way of dealing with future problems - therefore, it is of utmost importance in societies with high uncertainty avoidance and high future orientation. Planning in turn, may help in the implementation process, in particular for incremental innovation (Osburn \& Mumford, 2006; West, 2002).

\section{Individualism and collectivism}

Cultures with high individualism ${ }^{1}$ favor freedom of action, personal initiative, and independence which are values and practices that facilitate creativity (Jones \& Davis, 2000). The sparse empirical evidence indeed suggests that overall individualism provides an advantage for the rate of innovation of nations (Shane, 1993). However, organizational innovation is a collective endeavor and individualism may have dysfunction consequences on the convergence and alignment of people's activities and may lead to conflict among individuals (Nakata \& Sivakumar, 1996). The innovation process necessitates a certain degree

\footnotetext{
${ }^{1}$ There are two dimensions of individualism and collectivism in the GLOBE study - that differ in the focus institutional individualism focuses on large collectives, such as big corporations and the nation, while in-group individualism focuses on the family and the small group (Gelfand, Bhawuk, Hishi, \& Bechtold, 2004). There are some cultures where the two dimensions are similar (such as China, Germany which are very high or low on both respectively), but they may also diverge as in Zimbabwe, USA, and Brazil. As past research has not yet examined differential consequence of the two dimensions for innovation, we discuss overall individualism.
} 
of convergence and alignment, for instance, when ideas that closely build on each other are needed or when employees need to refine other people's ideas.

Leadership needs to walk the fine line between promoting and strengthening the individualistic behaviors that create the variety needed for innovation and fostering the convergent forces necessary for collective action. In order to unleash the potential of individualism for innovation, leaders can provide opportunities for unconstrained individual creativity, enable competition and an internal market of ideas, and reward the person with the best ideas (e.g., Eisenberger \& Rhoades, 2001). Potential integrating mechanisms by which leaders can foster convergent processes are communicating a strong vision that aligns team members, increasing interdependent tasks and internal communication, and building a cohesive team climate.

Souder and Jenssen (1999) provided evidence that integration mechanisms are particularly important in highly individualistic societies. Integration mechanisms between research and marketing departments during new product development were more important for project success in the U.S. than in Scandinavia. Frequent contact between research and marketing departments and competence of project managers are examples of integration mechanisms that were more important in the U.S. In contrast, in the cultural environment of Scandinavia that emphasizes solidarity and cooperation, explicit attempts to promote integration were of less concern because social linkages and high degrees of self-coordination were present.

According to our theoretical perspective, collectivistic cultures have different strengths and weakness for innovation than individualistic cultures. In collectivist cultures, individuals strongly derive their identity from the social system they are embedded in such as their team, organization, and nation. Their actions are aimed at collective goals and aligned with the norms of the social system (Triandis, 1995). Leaders can make use of the convergent force of 
collectivism that aligns activities of different employees (Nakata \& Sivakumar, 1996). By emphasizing the meaningfulness of creativity and innovation for the welfare of the lager social context, motivation for innovation may be increased. Also team rather than individual level rewards have been suggested as effective for motivation in collectivist cultures (Triandis, 1995). In a collectivist cultural context, leaders should build on intact social structures that have grown over time and facilitate social relationships as well as selfregulatory processes in teams.

A weakness of collectivism for innovation is that it can suppress the variety of ideas and potential actions that is fundamental for innovation (Herbig \& Dunphy, 1998). We therefore suggest that it is of particular importance that leaders take decisive action to promote the variety innovation requires. Examples of potential strategies are: increasing the frequency of communication of employees with people external to a team or organization, providing employees exposure to new knowledge, challenging established view points in a non-threatening way, acting as a role model of creativity.

Innovation often has disruptive consequences such as organizational restructuring and manpower flows. This may be perceived as a threat to identity in collectivist cultures. We therefore suggest that there is a particular need in collectivist cultures that leaders emphasize stability of social relationships and norms in addition to stimulating innovation. This will succeed more likely if an incremental, step-by-step approach is pursued such that the outcome of innovation is a transformation of what was already there, rather than the creation of something entirely novel and foreign.

\section{Power distance}

Power distance refers to the acceptance of hierarchical structures and unequal distribution of power and resources in a culture. Countries with low power distance have been 
found to produce more innovation (Shane, 1993). Low power distance facilitates innovative behavior because individuals dare to challenge the status quo and autonomously pursue ideas even if supervisors show resistance (Shane, Venkataraman, \& MacMillan, 1995). In contrast, people in high power distance cultures conform to organizational rules and regulations and do not display exploratory behavior without permission by their supervisors. A further barrier for innovation in high power distance cultures is the tendency to maintain established power structures. Innovation can face resistance because it is often accompanied by changes in the distribution of power. Promising new products developed in a new business unite may, for instance, shift attention of top management and the distribution of resources in favor of the new business unit at the cost of established business units.

Although cultures with higher power distance have these disadvantages, there are certain aspects of power distance that can be leveraged for innovation (Nakata \& Sivakumar, 1996). In a high power distance culture, a leader can build a system in which followers implement leaders' directives precisely. High power distance may thereby contribute to fast, top-down implementation of innovation. The success of such an approach depends on the leader's knowledge, creativity and leadership abilities because creativity and decision-making reside primarily with the leader (Murphy et al., 1992). Moreover, a leader may need to compensate for the lack of informal communication between people at different levels of the hierarchy that is characteristic of high power distance. Frequent communication is pivotal for innovation due to its limited predictability. Leaders in high power distance cultures may therefore need to set up elaborate communication channels and feedback systems that help with monitoring the progress of an innovation process and have the relevant information available to make effective decisions.

We assume that leaders in low power distance cultures face different challenges during the process of innovation than leaders in high power distance cultures. When innovation 
requires streamlined collective action, leaders in low power distance cultures may find less acceptance for their decisions if they rely only on their position power. As with highly individualistic cultures, we suggest that a strong vision can help to align followers. Moreover, leader will be more effective if they explain their decisions and persuade employees.

\section{Performance orientation}

Performance orientation implies a strong emphasis on performance issues at work such as a focus on working hard and getting things done. On the team level, task orientation which reflects performance orientation has been shown to have an important relationship with team innovativeness, in particular with administrative effectiveness of innovation (Huelsheger, Anderson, \& Salgado, 2009a; West \& Anderson, 1996). Although performance orientation has many beneficial consequences for innovation, we assume that it may reduce the playfulness that is often characteristic of a high degree of creativity. Thus, leaders who work in a highly performance oriented society, such as China or the US, may have to increase the playfulness of the work force - maybe it is this reason that many Silicon Valley firms provide playrooms with often "silly" games. A further route leaders may take to channel high performance orientation towards innovation is by creating and emphasizing the association between innovation and performance. Employees in performance oriented cultures may be particularly responsive if leaders set goals that emphasize innovation and reward innovative behavior such that innovation is perceived as an important aspect of performance. In low performance oriented society a lack of a playful approach towards work should be less of a concern (unfortunately, none of the countries displayed in Table 3 is low on performance orientation). In such cultures, challenges for leadership are to energize employees towards higher levels of effort and persistence and to focus employees efforts on creating tangible outcomes.

\section{Assertiveness}


Cultural assertiveness allows and accepts that individuals deviate from common norms, particularly so if the society is both individualistic and assertive. Showing initiative beyond what is expected and beyond what is allowed is higher in a society with high assertiveness (Den Hartog, 2004). These qualities of assertiveness may be functional for innovation. In an assertive culture (e.g. Germany, US, Brazil), it may be more accepted to initiate innovation and it may be easier for a leader to foster radical innovations.

A downside of assertiveness is that it can interfere with the willingness of people to cooperate and may lead to conflict. Innovation implementation in organizations hinges on cooperation and conflict has been found to be overall dysfunctional (De Dreu \& Weingart, 2003). Thus, the same cultural characteristic that enables the persistent pursuit of a radically new idea, may evoke resistance during the innovation process.

Leaders need to consider the two-sided role of assertiveness in the innovation process. In an assertive society, leaders may need to compensate for the lack of smoothness among their followers by emphasizing harmony, facilitating cooperation and preventing conflict. Also, the leaders' networking ability may be more important in an assertive society than in a non-assertive society, because it can counterbalance tensions that arise as a consequence of innovation initiatives. In contrast, in a non-assertive society leaders may have to compensate for a one-sided focus on harmony and consensus-seeking. Leaders may point out to the value of divergent viewpoints and individual initiatives and demand that their followers persistently pursue ideas.

\section{Gender egalitarianism}

On the most basic level, gender egalitarianism should increase the base rate of innovations because it broadens the human resource base by including women more frequently in jobs that require creativity and innovation. Women's economic activities are 
enhanced in highly gender egalitarian societies (Emrich, Denmark, \& Den Hartog, 2004). Moreover, since females are often more socially skilled than men, gender egalitarianism may enhance implementation of innovation because more females will be included as leaders in organizations. However, there may also be cases where raw rugged masculinity may prove functional for innovation (Singh, 2006). In the case where a radical innovation needs to be defended against large societal resistance, societies with a low degree of gender egalitarianism may have an advantage. We know of no study that has examined implications of gender egalitarianism for innovation. However, we believe that leaders can and have to deal with the specific challenges of high or low gender egalitarianism just like with any other cultural dimension.

\section{Humane orientation}

Humane orientation is a complex societal practice. The societal practice is negatively related to humane oriented leadership and to GDP of nations (Kabasakal \& Bodur, 2004) and positively related to authoritarianism in a society (Schloesser, Frese, \& al, 2010). Humane orientation includes societal tolerance for errors. High error tolerance suggests a high level of psychological safety and high error management culture which have been shown to be related to innovativeness of firms and teams (Frese et al., 2010; Huelsheger et al., 2009a). Moreover, humane orientation with its emphasis on harmony may increase trust in teams and provide a high degree of support. However, harmony requires conformity and the inherent conservatism of humane orientation may pose a challenge for leaders in high humane oriented societies because deviance from teams and society may not be acceptable.

\section{Conclusion}

Our proposed new look on leadership for innovation focuses on the dualities of innovation and the dynamic processes through which innovation unfolds (Bledow et al., 
2009a). The concept of ambidexterity informs us that leaders need to develop a broad set of leadership tactics to enable the dualities of innovation captured by terms such as creation and implementation. As the process of innovation unfolds, the importance of each sides of a duality and the set of leader behaviors that are effective alternate in an iterative manner. Leaders therefore need to constantly adapt their approach to the dynamics of innovation and need to take into account strengths and weakness of their followers to ensure an overall balance of forces (Bledow et al., 2009b; Rosing et al., 2010).

Culture adds yet another layer of complexity for a leader who aspires to increase innovativeness and - more important - innovation success. Cultural factors can contribute to innovation and they can make innovation success more difficult. Cultural factors need to be exploited and used, facilitated, and compensated for depending upon the specific requirement of the innovative process and the specifics of a culture. Although there is no simple recipe that can be given to practitioners and although the research base from which inferences can be drawn is weak, there is a clear proposition: Do not fall prey to simple-minded conclusions on culture, leadership, and innovation. Claims that a certain culture or leadership approach is unambiguously and always good for innovation are most likely wrong. Innovation success is a question of how cultural factors are managed and how leaders combine different leadership approach in a context sensitive manner.

This chapter has attempted to produce a certain set of ideas of how culture influences the innovation process and how it can be managed. It will help to know that in this process, there are many chances for leaders to do something wrong but there are also many avenues to do something right. Sensibility, adaptation, changeability, experimentation, cultural awareness, general leadership skills, and the willingness to be surprised by the complexity of the process may all contribute to the success of leadership for innovation. 


\section{References}

Anderson, N., De Dreu, C. K., \& Nijstad, B. A. (2004). The routinization of innovation research: A constructively critical review of the state-of-the-science. Journal of Organizational Behavior, 25(2), 147-173.

Andriopoulos, C., \& Lewis, M. W. (2009). Exploitation-exploration tensions and organizational ambidexterity: Managing paradoxes of innovation. Organization Science, 20, 696-717.

Arbel, I., \& Erez, M. (2008). “Team sharing and reflexivity as a lever to innovation in product development teams.'” EU-US Early Career Researcher Conference on Research and Innovation Studies. Organized by the PRIME Network of Excellence, University of Twente, Enschede, The Netherlands.

Benner, M. J., \& Tushman, M. (2003). Exploitation, Exploration, and Process Management: The Productivity Dilemma Revisited. Academy of Maganement Review, 27, 238-256.

Bledow, R., \& Farr, J. (2009). Leading the implementation of new ideas: Is there one best way? Paper presented at the Annual Meeting of the Society of Industrial and Organizational Psychology

Bledow, R., Frese, M., Anderson, N. R., Erez, M., \& Farr, J. L. (2009a). A dialectical perspective on innovation: Conflicting demands, multiple pathways, and ambidexterity. Industrial and Organizational Psychology: Perspectives on Science and Practice, 2, 305-337.

Bledow, R., Frese, M., Anderson, N. R., Erez, M., \& Farr, J. L. (2009b). Extending and refining the dialectic perspective on innovation: There is nothing as practical as a good 
theory; nothing as theoretical as a good practice. Industrial and Organizational Psychology: Perspectives on Science and Practice, 2, 363-373.

Buijs, J. (2007). Innovation leaders should be controlled schizophrenics. Creativity and Innovation Management, 16, 203-210.

Dayan, M., Di Benedetto, C. A., \& Colak, M. (2009). Managerial trust in new product development projects: its antecedents and consequences. $R \& D$ Management, 39, 2137.

De Dreu, C. K. W., \& Weingart, L. R. (2003). Task versus relationship conflict, team performance, and team member satisfaction: A meta-analysis. Journal of Applied Psychology, 88, 741-749.

Den Hartog, D. N. (2004). Assertiveness. In R. J. House, P. J. Hanges, M. Javidan, P. W. Dorfman \& V. Gupta (Eds.), Cultures, Leadership and Organizations: A 62 Nation GLOBE Study (pp. 395-436). Thousand Oaks, Calif.: Sage.

Denison, D. R., Hooijberg, R., \& Quinn, R. E. (1995). Paradox and performance: Toward a theory of behavioral complexity in managerial leadership. Organization Science, 6, 524-540.

Eisenberger, R., \& Rhoades, L. (2001). Incremental effects of reward on creativity. Journal of Personality and Social Psychology, 81, 728-741.

Emery, F. E., \& Trist, E. L. (1969). Socio-technical systems. In F. E. Emery (Ed.), Systems thinking. London: Penguin.

Emrich, C. G., Denmark, F. L., \& Den Hartog, D. N. (2004). Cross-cultural differences in gender egalitarianism. In R. J. House, P. J. Hanges, M. Javidan, P. W. Dorfman \& V. 
Gupta (Eds.), Cultures, leadership and organizations: A 62 nation GLOBE study (pp. 343-394). Thousand Oaks, Calif.: Sage.

Farjoun, M. (2010). Beyond dualism: Stability and change as in duality. The Academy of Management Review, 35, 202-225.

Farr, J. L., Sin, H.-P., \& Tesluk, P. E. (2003). Knowledge Management Processes and Work Group Innovation. In L. V. Shavinina (Ed.), The international handbook on innovation (pp. 574-586). New York, NY: Elsevier Science.

Frese, M., Mertins, J. C., Hardt, J. V., Fischer, S., Flock, T., Schauder, J., et al. (2010). Innovativeness of firms and organizational culture: The role of error management culture and pro-initiative climate. in preparation.

Gebert, D., Boerner, S., \& Lanwehr, R. (2003). The risks of autonomy: Empirical evidence for the necessity of a balance management in promoting organizational innovativeness. Creativity and Innovation Management, 12, 41-49.

Gelfand, M. J., Bhawuk, D. P. S., Hishi, L. H., \& Bechtold, D. J. (2004). Individualism and collectivism. In R. J. House, P. J. Hanges, M. Javidan, P. W. Dorfman \& V. Gupta (Eds.), Culture, leadership, and organizations: The GLOBE study of 62 societies (pp. 437-512). Thousand Oaks, Calif.: Sage.

Gilson, L. L., Mathieu, J. E., Shalley, C. E., \& Ruddy, T. M. (2005). Creativity and Standardization: Complementary or Conflicting Drivers of Team Effectiveness? Academy of Management Journal, 48, 521-531.

Gupta, V., de Luque, M. S., \& House, R. J. (2004). Multisource construct validity of GLOBE scales. In R. J. House, P. J. Hanges, M. Javidan, P. W. Dorfman \& V. Gupta (Eds.), 
Cultures, Leadership and Organizations: A 62 Nation GLOBE Study (pp. 152-177).

Thousand Oaks, Calif.: Sage.

Hanges, P. J. (2004). Societal-level correlations among GLOBE societal culture scales. In R.

J. House, P. J. Hanges, M. Javidan, P. W. Dorfman \& V. Gupta (Eds.), Cultures, Leadership and Organizations: A 62 Nation GLOBE Study (pp. 733-736). Thousand Oaks, Calif.: Sage.

Hanges, P. J., \& Dickson, M. W. (2004). The development and validation of the GLOBE culture and leadership scales. In R. J. House, P. J. Hanges, M. Javidan, P. W. Dorfman \& V. Gupta (Eds.), Cultures, Leadership and Organizations: A 62 Nation GLOBE Study (pp. 122-151). Thousand Oaks, Calif.: Sage.

Herbig, P., \& Dunphy, S. (1998). Culture and innovation. Cross Cultural Management, 5, 1321.

Hoegl, M., \& Parboteeah, K. P. (2006). Autonomy and teamwork in innovative projects. Human Resource Management, 45, 67-79.

Hofstede, G. (1980). Culture's consequences: International differences in work related values. Beverly Hills, CA: Sage Publications.

Hofstede, G. (1991). Cultures and organizations. London: McGraw-Hill.

Homan, A. C., van Knippenberg, D., Van Kleef, G. A., \& De Dreu, C. K. W. (2007). Bridging faultlines by valuing diversity: Diversity beliefs, information elaboration, and performance in diverse work groups. Journal of Applied Psychology, 92, 1189-1199.

House, R. J., Hanges, P. J., Javidan, M., Dorfman, P. W., \& Gupta, V. (Eds.). (2004). Cultures, Leadership and Organizations: A 62 Nation GLOBE Study. Thousand Oaks CA: Sage. 
House, R. J., \& Javidan, M. (2004). Overview of GLOBE. In R. J. House, P. J. Hanges, M. Javidan, P. W. Dorfman \& V. Gupta (Eds.), (Eds.). (2004). Cultures, Leadership and Organizations: A 62 Nation GLOBE Study (pp. 9-28). Thousand Oaks CA: Sage.

Huelsheger, U. R., Anderson, N. R., \& Salgado, J. F. (2009a). Team-level predictors of innovation at work: A comprehensive meta-analysis spanning three decades of research. Journal of Applied Psychology, 94, 1128-1145.

Hulsheger, U. R., Anderson, N. R., \& Salgado, J. F. (2009b). Leadership and Innovation: A metaanalysis of main relationships and an investigation into cultural differences. Paper presented at the EAWOP conference, Santiago de Compostella.

Jansen, J. J. P., George, G., Van den Bosch, F. A. J., \& Volberda, H. W. (2008). Senior Team Attributes and Organizational Ambidexterity: The Moderating Role of Transformational Leadership. Journal of Management Studies, 45, 982-1007.

Javidan, M., House, R. J., \& Dorfman, P. W. (2004). A nontechnical summary of GLOBE findings. In R. J. House, P. J. Hanges, M. Javidan, P. W. Dorfman \& V. Gupta (Eds.), Cultures, Leadership and Organizations: A 62 Nation GLOBE Study (pp. 29-48). Thousand Oaks CA: Sage.

Jones, G. K., \& Davis, H. J. (2000). National culture and innovation: implications for locating global R\&D operations. Management International Review, 40, 11-40.

Kabasakal, H., \& Bodur, M. (2004). Humane orientation in societies, organizations, and leader attributes. In R. J. House, P. J. Hanges, M. Javidan, P. W. Dorfman \& V. Gupta (Eds.), Cultures, Leadership and Organizations: A 62 Nation GLOBE Study (pp. 564601). Thousand Oaks CA: Sage. 
Keller, R. T. (2006). Transformational Leadership, Initiating Structure, and Substitutes for Leadership: A Longitudinal Study of Research and Development Project Team Performance. Journal of Applied Psychology, 91, 202-210.

Kearney, E., \& Gebert, D. (2009). Managing Diversity and Enhancing Team Outcomes: The Promise of Transformational Leadership. Journal of Applied Psychology, 94, 77-89.

Lewis, M. W. (2000). Exploring paradox: Toward a more comprehensive guide. Academy of Management Review, 25, 760-776.

Lewis, M. W., Welsh, M. A., Dehler, G. E., \& Green, S. G. (2002). Product development tensions: Exploring contrasting styles of product management. Academy of Management Journal, 45, 546-564.

Lin, L. H. (2009). Effects of national culture on process management and technological innovation. Total Quality Management \& Business Excellence, 20, 1287-1301.

March, J. G. (1991). Exploration and exploitation in organizational learning. Organization Science, 2, 71-87.

McGrath, J. E. (1962). Leadership behavior: Some requirements for leadership training. Washington, DC: US Civil Service Commission, Office of Career Development.

Miron-Spector, E., Erez, M., \& Naveh, E. (2006). The personal attributes that enhance individual versus team innovation. Paper presented at the Annual Meeting of the Academy of Management.

Miron, E., Erez, M., \& Naveh, E. (2004). Do personal characteristics and cultural values that promote innovation, quality, and efficiency compete or complement each other? Journal of Organizational Behavior, 25, 175-199. 
Morgeson, F. P. (2005). The External Leadership of Self-Managing Teams: Intervening in the Context of Novel and Disruptive Events. Journal of Applied Psychology, 90, 497-508.

Murphy, S. E., Blyth, D., \& Fiedler, F. E. (1992). Cognitive resource theory and the utilization of the leader's and group members' technical competence. The Leadership Quarterly, 3, 237-255.

Nakata, C., \& Sivakumar, K. (1996). National Culture and New Product Development: An Integrative Review. Journal of Marketing, 60, 61-72.

Ohly, S., Sonnentag, S., \& Pluntke, F. (2006). Routinization, work characteristics and their relationships with creative and proactive behaviors. Journal of Organizational Behavior, 27, 257-279.

Osburn, H. K., \& Mumford, M. D. (2006). Creativity and planning: Training interventions to develop creative problem-solving skills. Creativity Research Journal, 18, 173-190.

Rosing, K., Rosenbusch, N., \& Frese, M. (2010). Ambidextrous Leadership in the Innovation Process. In A. Gerybadze, U. Hommel, H. W. Reiner \& D. Thomaschewski (Eds.), Innovation and International Corporate Growth: Strategy, Processes, and Performance (pp. 191-204). Heidelberg: Springer.

Schloesser, O., Frese, M., \& al, e. (2010). Humane orientation as a new cultural dimension A validation study on the GLOBE Scale in 25 Countries. University of Giessen: unpublished manuscript.

Shalley, C. E. (1991). Effects of productivity goals, creativity goals, and personal discretion on individual creativity. Journal of Applied Psychology, 76, 179-185. 
Shalley, C. E., Zhou, J., \& Oldham, G. R. (2004). The effects of personal and contextual characteristics on creativity: Where should we go from here? Journal of Management, 30, 933-958.

Shane, S. (1992). Why do some societies invent more than others? Journal of Business Venturing, 7, 29-46.

Shane, S. (1993). Cultural influences on national rates of innovation. Journal of Business Venturing, 8, 59-73.

Shane, S., Venkataraman, S., \& MacMillan, I. (1995). Cultural differences in innovation championing strategies. Journal of Management, 21, 931-952.

Sheremata, W. A. (2000). Centrifugal and centripetal forces in radical new product development under time pressure. Academy of Management Review, 25, 389-408.

Shin, S. J., \& Zhou, J. (2007). When is educational specialization heterogeneity related to creativity in research and development teams? Transformational leadership as a moderator. Journal of Applied Psychology, 92, 1709-1721.

Singh, S. (2006). Cultural differences in, and influences on, consumers' propensity to adopt innovations. International Marketing Review, 23(2), 173-191.

Souder, W. E., \& Jenssen, S. A. (1999). Management practices influencing new product success and failure in the United States and Scandinavia: a cross-cultural comparative study.

Stephan, U., \& Uhlaner, L. M. (in press 2010). Performance-based vs socially supportive culture: A cross-national study of descriptive norms and entrepreneurship. Journal of International Business Studies. 
Stogdill, R. M., \& Coons, A. E. (1957). Leader behavior: Its description and measurement. Columbus, OH: Ohio State University College of Administrative Science.

Triandis, H. C. (1995). Individualism and collectivism. Boulder, Colorado: Westview Press.

Tushman, M. L., \& O'Reilly, C. A., III. (2006). Ambidextrous organizations: Managing evolutionary and revolutionary change. In D. Mayle (Ed.), Managing innovation and change (3rd ed.) (pp. 170-184). Thousand Oaks, CA: Sage Publications Ltd.

Van Knippenberg, D., De Dreu, C. K. W., \& Homan, A. C. (2004). Work group diversity and group performance: An integrative model and research agenda. Journal of Applied Psychology, 89, 1008-1022.

West, M. A. (2002). Sparkling fountains or stagnant ponds: An integrative model of creativity and innovation implementation in work groups. Applied Psychology: An International Review, 51, 355-386.

West, M. A., \& Anderson, N. R. (1996). Innovation in top management teams. Journal of Applied Psychology, 81, 680-693.

Westwood, R., \& Low, D. R. (2003). The multicultural muse: culture, creativity and innovation. International Journal of Cross Cultural Management, 3, 235. 
Figure 1

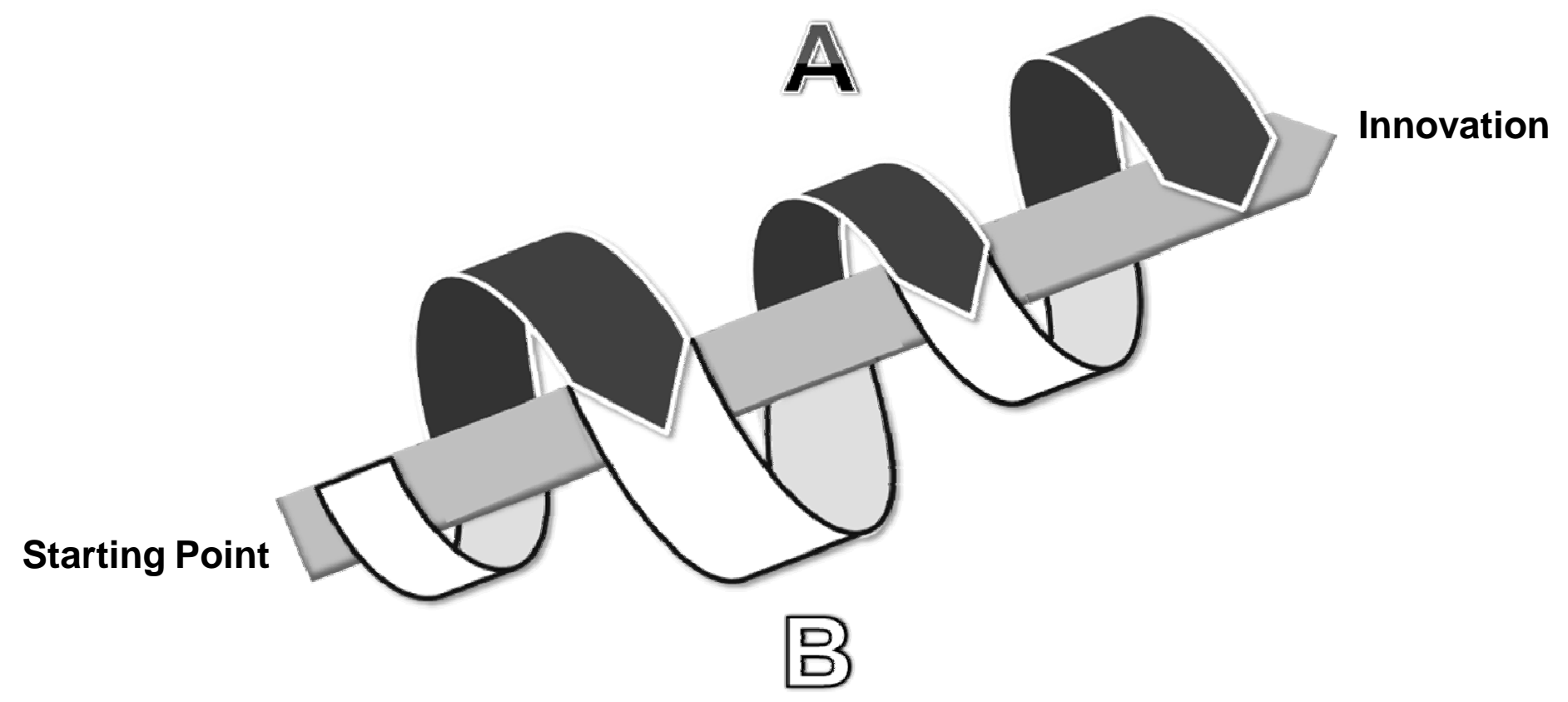

Figure 1. Alternating between the complementary poles (A and B) of a dualism: e.g. alternating between exploration and exploitation, creation and implementation, knowledge generation and knowledge integration (reprint from Bledow, Frese, Anderson, Erez, \& Farr, 2009b) 
Table 1

\section{Germany ${ }^{1}$}

China

Brazil

Zimbabwe

USA

\begin{tabular}{|c|c|c|c|c|c|c|c|c|c|c|}
\hline & Rank & Exact & Rank & Exact & Rank & Exact & Rank & Exact & Rank & Exact \\
\hline $\begin{array}{l}\text { Uncertainty avoidance is defined as the extent to which a } \\
\text { collective strives to avoid uncertainty by reliance on social } \\
\text { norms, rituals, and bureaucratic practices „to alleviate the } \\
\text { unpredictability of future events“. }\end{array}$ & A & 5.16 & A & 4.94 & $\mathrm{C}$ & 3.60 & B & 4.15 & B & 4.15 \\
\hline $\begin{array}{l}\text { Future orientation is the degree to which a society encourages } \\
\text { and rewards ,future-oriented behaviors such as delaying } \\
\text { gratification, planning, and investing in the future“. }\end{array}$ & B & 4.27 & $\mathrm{C}$ & 3.75 & $\mathrm{~B}$ & 3.81 & $\mathrm{C}$ & 3.77 & $\mathrm{~B}$ & 4.15 \\
\hline \multicolumn{11}{|l|}{$\begin{array}{l}\text { Collectivism (vs. individualism) reflects the degree to which } \\
\text { individuals are integrated into groups within an organization or } \\
\text { society: }\end{array}$} \\
\hline Institutional collectivism & $\mathrm{C}$ & 3.79 & $\mathrm{~A}$ & 4.77 & $\mathrm{C}$ & 3.83 & B & 4.12 & $\mathrm{~B}$ & 4.20 \\
\hline In-group collectivism & $\mathrm{C}$ & 4.02 & $\mathrm{~A}$ & 5.80 & $\mathrm{~B}$ & 5.18 & A & 5.57 & $\mathrm{C}$ & 4.25 \\
\hline $\begin{array}{l}\text { Power distance is the degree to which members of a collective } \\
\text { expect power to be distributed unequally }\end{array}$ & B & 5.25 & B & 5.04 & A & 5.33 & A & 5.67 & B & 4.88 \\
\hline $\begin{array}{l}\text { Performance orientation refers to the extent to which a } \\
\text { „society encourages and rewards group members for } \\
\text { performance improvement and excellence“ }\end{array}$ & B & 4.25 & A & 4.45 & B & 4.04 & B & 4.24 & A & 4.49 \\
\hline $\begin{array}{l}\text { Assertiveness is "the degree to which individuals are assertive, } \\
\text { dominant, and aggressive in their relationships with others“. }\end{array}$ & A & 4.55 & B & 3.76 & A & 4.20 & B & 4.06 & A & 4.55 \\
\hline $\begin{array}{l}\text { Gender egalitarianism is the extent to which a society } \\
\text { „minimizes gender inequality“. }\end{array}$ & B & 3.10 & B & 3.05 & B & 3.31 & B & 3.04 & A & 3.34 \\
\hline $\begin{array}{l}\text { Humane orientation is the degree to which a society } \\
\text { „encourages and rewards individuals for being fair, altruistic, } \\
\text { generous, caring, and kind to others" (also forgiving of errors). }\end{array}$ & $\mathrm{D}$ & 3.18 & B & 4.36 & $\mathrm{C}$ & 3.66 & B & 4.45 & $\mathrm{C}$ & 4.17 \\
\hline
\end{tabular}

A means highest of countries, D means lowest cluster of countries (in some categories, there are only three clusters: A, B, C), ${ }^{1}$ The ranking and exact values refer to the states of former West Germany, version of 17-03-00 of GLOBE, definitions from Javidan et al. (2004, p. 30) 
Table 2

\section{Functional influences of culture} on innovation

Future orientation and A focus on the future stimulates innovation uncertainty avoidance

High degrees of planning facilitate

implementation and incremental innovation

\section{Collectivism}

Facilitates incremental innovation and collective action

Followers can be aligned behind a shared vision

\section{Power distance}

\section{Performance}

orientation

Assertiveness

Promotes initiation and persistence of

Gender egalitarianism Gender diversity helps broaden the human

Humane orientation innovation initiatives

Facilitates the pursuit of radical innovation resource base for innovation

Higher levels of women in leadership positions improve social processes

Facilitates streamlined implementation of novel ideas and enforcement of radical innovations

Promotes effort, persistence and a focus on useful and doable innovations

Increases exploratory behavior through trust and error tolerance

\section{Dysfunctional influences of culture} on innovation

Constrains exploratory behavior and can lead to rigidity

Hinders risk taking and radical innovation

Hinders individual initiatives and radical innovations that threaten a collective

Reduces the level of diversity and individual deviation from group norms

Employees do not explore without permission of their supervisor

There is a high dependability on supervisors during the implementation process

Hinders a playful mind-set that is focused on exploring and learning

Can lead to conflict and disrupt smooth team processes

Can interfere with implementation if cooperation is crucial

Hinders a macho culture that may help for radical innovation through rugged individualism

Hinders innovation through a emphasis on harmony and conformity

\section{Implications for leaders}

Point out future opportunities and problems and emphasize the necessity to act now

Counterbalance rigidity by stimulating and rewarding explorative and flexible behavior

Focus rewards and competition on collective level and stimulate divergent viewpoints within a collective

Emphasize the meaningfulness of innovation for the collective and build on intact social structures

Initiate, structure and monitor the innovation process

Encourage autonomous initiatives, provide managerial support for innovators, ensure vertical information flows

Link innovation to performance through goal-setting and rewards

Stimulate a playful and creative mind-set

Allow for and provide support for individual initiatives

Counterbalance assertiveness by building social networks and by fostering harmony

Emphasize the benefits of diversity

Provide high support for individuals and build on trust and harmony 